\title{
Anthropometric Indices Associated with Variation in Cardiovascular Parameters among Primary School Pupils in Ile-Ife
}

\author{
Adedeji G. Abiodun, ${ }^{1}$ Michael O. Egwu, ${ }^{2,3}$ and Rufus A. Adedoyin ${ }^{2,3}$ \\ ${ }^{1}$ Department of Physiotherapy, Obafemi Awolowo University Teaching Hospitals Complex, Ile-Ife, Nigeria \\ ${ }^{2}$ Department of Medical Rehabilitation, Obafemi Awolowo University, Ile-Ife, Nigeria \\ ${ }^{3}$ Department of Physiotherapy, Obafemi Awolowo University Teaching Hospitals Complex, P.M.B 5538 Ile-Ife, Nigeria
}

Correspondence should be addressed to Michael O. Egwu, egwumo@yahoo.com

Received 4 November 2010; Revised 27 March 2011; Accepted 29 March 2011

Academic Editor: G. Ogedegbe

Copyright ( 2011 Adedeji G. Abiodun et al. This is an open access article distributed under the Creative Commons Attribution License, which permits unrestricted use, distribution, and reproduction in any medium, provided the original work is properly cited.

\begin{abstract}
Purpose. This study investigated the anthropometric indices associated with variations in cardiovascular parameters among primary school pupils in Ile-Ife. Method. One thousand and twenty-six pupils (age range 6-14 years, mean age 10.12 years) from ten schools were recruited with parents' informed consent. Anthropometric (Height (Ht), Weight (Wt), Abdominal Circumference (AC)) and cardiovascular (Systolic Blood Pressure (SBP), Diastolic Blood Pressure (DBP), Heart Rate (HR)) parameters were measured using standard instruments and procedures. Blood pressure (BP) was measured after ten minutes of quiet sitting. Body Mass Index (BMI), Rate Pressure Product (RPP) and Pulse Pressure (PP) were estimated. Results. Age, Ht, Wt, BMI, and AC correlated significantly $(P<.01)$ with BP and PP. AC and BMI were predictors of BP, HR, RPP, and PP. Conclusion. Significant correlations exist between age, $\mathrm{Ht}, \mathrm{Wt}, \mathrm{BMI}, \mathrm{AC}$, and $\mathrm{BP}$ with weight being a more viable predictor of SBP and age a more viable predictor of DBP.
\end{abstract}

\section{Introduction}

Hypertension is known to be a direct or indirect cause of death globally $[1,2]$. Findings from previous longitudinal studies of Blood Pressure (BP) suggests that essential hypertension in adults can be detected in early life $[3,4]$. Because of the public health value of prevention of hypertension, a lot of work has been done to find out the prevalence of childhood hypertension [3-5]. Part of the findings of these studies is that prevalence of hypertension in children has racial and rural-urban variations $[3,4]$.

In African children, higher risks of cardiovascular disease have been found among Urbanites than rural dwellers, however, no consistent trend was found along socioeconomic and ethnic lines [4-6]. These inconsistencies in the trend of essential hypertension in Africa have made it difficult to extrapolate adult risk for high BP from a child's BP. However, studies have been conducted in the past to identify anthropometric indices that can be used as markers of child $\mathrm{BP}$ and Heart Rate (HR) in Africa and other continents $[4,7]$. These studies have shown that BP in children is closely related to Height (Ht), Weight (Wt), Body Mass Index (BMI), Ponderosity Index (PI), skin fold thickness, and midupper arm circumference. However, the few studies that have examined this relationship among Nigerian children $[4,6]$ have not explored the relationship of Abdominal Circumference (AC) to their BP and HR whereas previous studies have highlighted its important relationship with obesity and abdominal adiposity [8-11]. In the year 2000, Savva et al. [7] reported that abdominal circumference and waist-to-hip ratio were better predictors of cardiovascular disease risk factors in children than BMI.

One of the comprehensive studies in the area of Nigerian child anthropometry and cardiovascular risk factors was the study of Balogun et al. [4]. They observed significant correlation between anthropometric (Wt, Ht, BMI, and upper-arm 
circumference) and cardiovascular (Systolic Blood Pressure (SBP), Diastolic Blood Pressure (DBP), HR, Rate Pressure Product (RPP), and Pulse Pressure (PP)) parameters of Nigerian children. This study found a $4 \%$ prevalence of hypertension among these children and noted that weight was the most viable predictor of $\mathrm{BP}$ and resting myocardial oxygen consumption. They also recommended that $\mathrm{Wt}$ norms rather than age be used in evaluating abnormal $\mathrm{BP}$ levels of Nigerian children.

It is important to know the BP relationship with $\mathrm{AC}$ of Nigerian children and if there are changes in the reported relationship between anthropometric and cardiovascular parameters among children in Nigeria. This is because the country's economy have been changing and population increasing over the past two decades. Information derived will help health professionals to adjust to the current trend and policy makers to evolve preventive measures to cope with changes in cardiovascular risk factors.

This study therefore examined (1) the relationship of Wt, $\mathrm{Ht}, \mathrm{BMI}$, and $\mathrm{AC}$ with $\mathrm{BP}$ and $\mathrm{HR}$ of school age children in Nigeria; (2) which of these anthropometric parameters is the most viable predictor of $\mathrm{BP}$ ?

\section{Methods}

2.1. Participants. One thousand and twenty-six (512 males and 514 females) apparently healthy primary school pupils whose ages ranged from 6 to 14 years (mean age $=10.12 \pm$ 2.46 years) in ten public (8) and private (2) primary schools in Ile-Ife, Nigeria were recruited for the study. Ile-Ife is an urban city in Osun state of Nigeria with 10 wards (city areas) and a population of 355,341 people (male $=176,707$; female 178,634 ) based on 2006 population census. To select the participating primary schools, the list of primary schools was obtained from the local schools authority and separated according to the city areas where they are located without minding whether they were public or private schools. Schools in the same ward were written out on small sheets of paper, which were folded and a neutral person was asked to pick one from each ward.

Before the commencement of the study, informed consent of the parents of the pupils was sought and ethical clearance obtained from the ethics and research committee of Obafemi Awolowo University Teaching Hospitals Complex, Ile-Ife. The participants were screened to eliminate any disability such as infantile poliomyelitis or limb length discrepancy that may make measurement of anthropometric and cardiovascular parameters difficult.

2.2. Procedure. On arrival into a class, the names of the pupils were written out alphabetically on a sheet of paper, 18 names were then selected from the list by selecting every $3 \mathrm{rd}$ name. Height was measured using a validated height metre. The subjects stood erect, barefoot on a flat surface, with the occiput, upper back, buttocks, and heels, touching the height metre. In line with the view of Steele and Spurgeon [12], the upper margin of the external auditory canal opening was in the Frankfurt horizontal plane, and the point of greatest $\mathrm{Ht}$ to the nearest $0.1 \mathrm{~cm}$ was then marked on the height metre.
Weight was measured to the nearest $0.1 \mathrm{Kg}$ with a weighing scale (Hanson Company, Ireland). Abdominal circumference was measured to the nearest $0.1 \mathrm{~cm}$ below the rib cage and above the umbilicus at the end of normal expiration using an inelastic tape (Butterfly, China). All measurements were taken by the same examiner within the school premises with subjects on minimum clothing. Blood pressure was measured once after ten minutes of quiet sitting with a standardized aneroid sphygmomanometer and a stethoscope (U-MEC, China). Heart rate was measured by auscultation for 30 seconds and later multiplied by two to get the HR per minute. The subject was comfortably seated in a chair with the arm well supported with a pillow.

2.3. Computations. The PP and PI were calculated using the formula PP $=\mathrm{SBP}-\mathrm{DBP}[13]$ and $\mathrm{PI}=\mathrm{Wt} / \mathrm{Ht}^{3}$ [4]. The BMI was obtained by dividing the $\mathrm{Wt}$ by the square of the $\mathrm{Ht}$, that is, $\mathrm{BMI}=\mathrm{Wt} / \mathrm{Ht}^{2}$ [4], while $\mathrm{RPP}$ was evaluated using the formula: $\mathrm{RPP}=\mathrm{SBP} \times \mathrm{HR}$ [4]. Mean Arterial Pressure (MAP) was estimated using the formula $\mathrm{MAP}=\mathrm{DBP}+1 / 3 \mathrm{PP}$.

\section{Data Analysis}

Data was analyzed using the Statistical Package for Social Sciences (SPSS) version 10.0. (SPSS Inc., Chicago, III, USA). Both descriptive (range, mean, median, mode, and standard deviation), and inferential statistics were used for data analysis. Pearson product moment correlation coefficient was computed to determine the correlation between the anthropometric characteristics of the pupils and their cardiovascular parameters. Student's $t$-test was used to determine the significant difference between the physical characteristics and physiological parameters of boys and girls. Stepwise regression analysis was employed to determine the combined and individual contribution of the anthropometric parameters towards the prediction of the criteria variables (cardiovascular parameters). The level of significance for all tests was set at $P<.05$.

\section{Results}

A total of 1032 pupils were initially selected, however, 6 children were not measured because when examined, 4 of them were febrile, while 2 had lower limb deformity. Therefore, this report is based on the data collected from 1026 apparently healthy school-age pupils (mean age of 10.12 \pm 2.46 years) who participated in this study. The physical characteristics and the resting physiological parameters of all the subjects are presented in Table 1. On the average, the SBP and DBP of the pupils were $98.63 \pm 12.38 \mathrm{mmHg}$ and $62.85 \pm 10.18 \mathrm{mmHg}$ with a 95th centile of 121.00 and 80 , respectively. The mean resting HR was $88.38 \pm$ 14.63 beats per minute. The mean RPP was $8725.54 \pm$ $1828.1 \mathrm{mmHg}$ beats per minute, while the mean PP was $35.79 \pm 8.64 \mathrm{mmHg}$.

The correlation between the anthropometric characteristic and the cardiovascular measures are presented in Table 2. Age was positively related to SBP, DBP, RPP, and PP but has inverse relationship with HR. The correlation between 
TABLE 1: Physical characteristics and resting physiological parameters of the subjects.

\begin{tabular}{|c|c|c|c|c|}
\hline \multicolumn{5}{|c|}{$N=1026$} \\
\hline \multirow[t]{2}{*}{ Variable } & \multicolumn{2}{|c|}{ Range } & \multirow[t]{2}{*}{ Mean \pm SD } & \multirow[t]{2}{*}{ 95th centile } \\
\hline & Min. & Max. & & \\
\hline Age (Yrs) & 6.00 & 14.00 & $10.12 \pm 2.46$ & 14.00 \\
\hline Height (m) & 0.97 & 1.40 & $1.31 \pm 0.13$ & 01.33 \\
\hline Weight (Kg) & 15.00 & 70.00 & $26.55 \pm 7.87$ & 42.00 \\
\hline $\mathrm{AC}(\mathrm{cm})$ & 49.00 & 92.00 & $59.37 \pm 5.50$ & 69.00 \\
\hline $\operatorname{BMI}\left(\mathrm{Kg} / \mathrm{m}^{2}\right)$ & 6.17 & 27.34 & $15.22 \pm 1.97$ & 18.67 \\
\hline $\mathrm{PI}\left(\mathrm{Kg} / \mathrm{m}^{3}\right)$ & 3.43 & 22.46 & $11.69 \pm 1.56$ & 14.55 \\
\hline $\mathrm{SBP}(\mathrm{mmHg})$ & 51.00 & 137.00 & $98.63 \pm 12.38$ & 121.00 \\
\hline DBP (mmHg) & 27.00 & 98.00 & $62.85 \pm 10.18$ & 80.00 \\
\hline HR (bpm) & 42.00 & 140.00 & $88.38 \pm 14.63$ & 112.00 \\
\hline RPP (mmHg bpm) & 2397.00 & 15540.00 & $8725.54 \pm 1828.1$ & 11704.80 \\
\hline PP (mmHg) & 8.00 & 69.00 & $35.79 \pm 8.64$ & 52.00 \\
\hline MAP (mmHg) & 84.20 & 108.33 & $92.66 \pm 7.99$ & 89.33 \\
\hline
\end{tabular}

Abbreviations: $\mathrm{AC}=$ Abdominal circumference, $\mathrm{HR}=$ Heart rate, $\mathrm{BMI}=$ Body Mass Index, $\mathrm{RPP}=$ Rate pressure product, $\mathrm{PI}=\mathrm{Ponderosity} \mathrm{index,} \mathrm{PP}=\mathrm{Pulse}$ pressure, $\mathrm{SBP}=$ Systolic blood pressure, $\mathrm{DBP}=$ Diastolic blood pressure.

TABLE 2: Correlation matrix showing the relationship between anthropometric indices and cardiovascular parameters.

\begin{tabular}{|c|c|c|c|c|c|c|c|c|c|c|c|}
\hline & Age & $\mathrm{HT}$ & $\mathrm{WT}$ & BMI & $\mathrm{AC}$ & PI & SBP & DBP & HR & RPP & PP \\
\hline Age (Yrs) & 1.000 & & & & & & & & & & \\
\hline $\mathrm{HT}(\mathrm{m})$ & $0.784^{* *}$ & 1.000 & & & & & & & & & \\
\hline WT (Kg) & $0.748^{* *}$ & $0.873^{* *}$ & 1.000 & & & & & & & & \\
\hline BMI $\left(\mathrm{Kg} / \mathrm{m}^{2}\right)$ & $0.441^{* *}$ & $0.364^{* *}$ & $0.756^{* *}$ & 1.000 & & & & & & & \\
\hline $\mathrm{AC}(\mathrm{cm})$ & $0.647^{* *}$ & $0.741^{* *}$ & $0.860^{* *}$ & $0.664^{* *}$ & 1.000 & & & & & & \\
\hline PI $\left(\mathrm{Kg} / \mathrm{m}^{3}\right)$ & $-0.183^{* *}$ & $-0.415^{* *}$ & 0.050 & $0.686^{* *}$ & 0.056 & 1.000 & & & & & \\
\hline $\mathrm{SBP}(\mathrm{mmHg})$ & $0.422^{* *}$ & $0.504^{* *}$ & $0.544^{* *}$ & $0.386^{* *}$ & $0.477^{* *}$ & $-0.015^{* *}$ & 1.000 & & & & \\
\hline DBP $(\mathrm{mmHg})$ & $0.372^{* *}$ & $0.425^{* *}$ & $0.406^{* *}$ & $0.225^{* *}$ & $0.375^{* *}$ & $-0.118^{* *}$ & $0.724^{* *}$ & 1.000 & & & \\
\hline $\mathrm{HR}(\mathrm{b} / \mathrm{m})$ & $-0.194^{* *}$ & $-0.234^{* *}$ & $-0.212^{*}$ & $-0.117^{* *}$ & $-0.214^{* *}$ & 0.063 & 0.042 & $0.143^{* *}$ & 1.000 & & \\
\hline $\begin{array}{l}\text { RPP } \\
(\mathrm{mmHg} b \mathrm{~m})\end{array}$ & $0.092 *$ & $0.114^{* *}$ & $0.150^{* *}$ & $0.127^{* *}$ & $0.110^{* *}$ & 0.032 & $0.615^{* *}$ & $0.543^{* *}$ & $0.806^{* *}$ & 1.000 & \\
\hline $\mathrm{PP}(\mathrm{mmHg})$ & $0.167 * *$ & $0.221^{* *}$ & $0.301^{* *}$ & $0.289^{* *}$ & $0.242^{* *}$ & $0.117^{* *}$ & $0.582^{* *}$ & $-0.140^{* *}$ & $-0.109^{* *}$ & $0.243^{* *}$ & 1.000 \\
\hline MAP (mmHg) & & & & & & & & & & & \\
\hline
\end{tabular}

${ }^{*} P<.05,{ }^{* *} P<.01$.

Key: HT = Height, WT = Weight, $\mathrm{AC}=$ Abdominal circumference, $\mathrm{PI}=$ Ponderosity index, $\mathrm{SBP}=$ Systolic blood pressure, $\mathrm{DBP}=\mathrm{Diastolic}$ blood pressure, $\mathrm{HR}$ $=$ Heart rate $\mathrm{RPP}=$ Rate pressure product, $\mathrm{PP}=$ Pulse pressure, $\mathrm{BMI}=$ Body mass index .

some anthropometric (age, $\mathrm{Ht}$, Wt, BMI, and $\mathrm{AC}$ ) and cardiovascular (BP, PP) parameters were positive and significant $(P<.01)$. However, HR had significant negative correlation with Age, Ht, BMI, and $\mathrm{AC}(P<.01)$, and Wt $(P<$ $.05)$. The correlation between PI and SBP was significant $(\mathrm{P}<.01)$ but was not significantly correlated with HR and RPP. As shown in Table 3, there were no significant gender variations in cardiovascular parameters. However, females were significantly $(P<.05)$ heavier and had significantly $(P<.05)$ higher AC and BMI than their male counterparts.

Table 4 summarized the results of the multiple and stepwise regression analysis for SBP. Weight (24.8\%), AC (2.0\%) and BMI (1.6\%) when combined contributed significantly $(P<.05)$ towards predicting $(28.4 \%)$ the levels of SBP.
Addition of BMI to Wt caused a variation of $1.6 \%$ in predicting SBP while addition of AC to Wt and BMI explained 2.0\% of the total variation in SBP. Age (9.7\%) and weight $(1.5 \%)$ accounted for $11.2 \%$ of the total variance in DBP (Table 5) while AC $(4.6 \%)$ and age $(0.7)$ were two viable predictors (5.3\%) of HR. The only determinant of RPP was Wt which accounted for $1.5 \%$ in its variance. Weight and BMI $(0.9 \%)$ contributed significantly towards the prediction of PP.

\section{Discussion}

This cross-sectional study investigated the relationship of some anthropometric and cardiovascular indices of school age Nigerian children. The main purpose of this research was 
TABLE 3: Comparison of male and female physical characteristics and cardiovascular parameters.

\begin{tabular}{|c|c|c|c|c|}
\hline Variables & $\begin{array}{c}\text { Male } \\
(\text { Mean } \pm \text { SD })\end{array}$ & $\begin{array}{c}\text { Female } \\
(\text { Mean } \pm \mathrm{SD})\end{array}$ & $t$-value & $P$-value \\
\hline Age (Yrs) & $10.2 \pm 2.5$ & $10.1 \pm 2.4$ & 0.73 & .56 \\
\hline Height $(\mathrm{m})$ & $1.3 \pm 0.1$ & $1.3 \pm 0.1$ & -0.90 & .08 \\
\hline Weight (Kg) & $26.2 \pm 6.8$ & $26.9 \pm 8.6$ & -1.15 & $.05^{*}$ \\
\hline $\mathrm{AC}(\mathrm{cm})$ & $59.2 \pm 4.6$ & $60.2 \pm 6.2$ & -2.53 & $.05^{*}$ \\
\hline $\mathrm{BMI}\left(\mathrm{Kg} / \mathrm{m}^{2}\right)$ & $15.1 \pm 1.8$ & $15.2 \pm 2.2$ & -0.04 & $.05^{*}$ \\
\hline $\mathrm{PI}\left(\mathrm{Kg} / \mathrm{m}^{3}\right)$ & $11.7 \pm 1.6$ & $11.6 \pm 1.5$ & 0.87 & .54 \\
\hline $\mathrm{SBP}(\mathrm{mmHg})$ & $97.0 \pm 12.5$ & $100.2 \pm 12.1$ & -3.53 & .78 \\
\hline DBP (mmHg) & $61.2 \pm 9.5$ & $64.4 \pm 10.5$ & -4.36 & .07 \\
\hline Heart rate (bpm) & $86.3 \pm 15.1$ & $90.4 \pm 13.9$ & -3.79 & .23 \\
\hline RPP (mmHg bpm) & $8388.8 \pm 1838.6$ & $9047.6 \pm 1756.8$ & -4.99 & .66 \\
\hline $\mathrm{PP}(\mathrm{mmHg})$ & $35.8 \pm 9.2$ & $35.8 \pm 8.1$ & 0.05 & .15 \\
\hline MAP (mmHg) & $73.2 \pm 11.4$ & $76.1 \pm 10.2$ & -3.34 & .56 \\
\hline
\end{tabular}

${ }^{*} P<.05$.

Key: $\mathrm{AC}=$ Abdominal circumference, $\mathrm{BMI}=$ Body mass index, $\mathrm{PI}=$ Ponderosity index, $\mathrm{SBP}=$ Systolic blood pressure, $\mathrm{DBP}=\mathrm{Diastolic}$ blood pressure, $\mathrm{RPP}=$ Rate pressure product, $\mathrm{PP}=$ Pulse pressure, $\mathrm{SD}=$ Standard deviation.

TABLE 4: Stepwise regression analysis summary for Systolic Blood Pressure (SBP) showing changes in multiple regression coefficient of determination $\left(R^{2}\right)$ with addition of different variables.

\begin{tabular}{lccc}
\hline Stages of analysis & $R^{2}$ & SEE & $F$ \\
\hline${ }^{1}$ Weight & 0.248 & 10.80 & $337.80^{* * *}$ \\
${ }^{2}$ Weight and BMI & 0.264 & 10.79 & $174.20^{* * *}$ \\
${ }^{3}$ Weight, BMI and AC & 0.284 & 10.76 & $118.60^{* * *}$ \\
\hline
\end{tabular}

Regression equation for the different stages of analysis: ${ }^{1} \mathrm{SBP}=76.53+0.84$ weight; ${ }^{2} \mathrm{SBP}=82.53+0.97$ weight -0.62 Body mass index; ${ }^{3} \mathrm{SBP}=$ $70.00+0.80$ weight -0.58 Body mass index +0.27 Abdominal circumference; ${ }^{4} \mathrm{SBP}=98.1+4.6 . \mathrm{SEE}=$ Standard error of estimate.

$* * *$ Significant $(P<0.01)$.

TABLE 5: Stepwise regression analysis summary for Diastolic Blood Pressure (DBP) showing changes in multiple regression coefficient of determination $\left(R^{2}\right)$ with addition of different variables.

\begin{tabular}{lccc}
\hline Stages of analysis & $R^{2}$ & SEE & $F$ \\
\hline${ }^{1}$ Age & 0.097 & 11.28 & $110.40^{* * *}$ \\
${ }^{2}$ Age and Weight & 0.112 & 11.19 & $64.67^{* * *}$ \\
${ }^{3}$ Age, Weight and BMI & 0.118 & 11.16 & $45.70^{* * *}$ \\
\hline
\end{tabular}

Regression equation for the different stages of analysis: ${ }^{1} \mathrm{DBP}=47.87+1.51$ age ${ }^{2} \mathrm{DBP}=46.69+0.88$ age +0.29 weight $;{ }^{3} \mathrm{DBP}=53.46+0.68$ age +0.46 weight -0.63 Body mass index, ${ }^{4} \mathrm{DBP}=62.29+4.82 . \mathrm{SEE}=$ Standard Error of Estimate.

$* * *$ Significant $(P<0.01)$.

to find out if some of the previously established anthropometric determinants of hypertension in Nigerian children are still viable while exploring the usefulness of other parameters. It was observed that significant correlations still exist between anthropometric parameters (age, $\mathrm{Ht}, \mathrm{Wt}, \mathrm{BMI}$, and AC) and BP. Weight (24.8\%) was found to be the most viable predictor of SBP while age was the best determinant of DBP $(9.7 \%)$. Although weight contributed little to the prediction $(1.5 \%)$ of DBP age did not contribute to the prediction of SBP. This finding is consistent with the report of Andy et al. [13] but not with that of Balogun et al. [4]. Andy et al. reported that age and Wt were the two most important determinants of BP levels of Nigerian children, but the influence of Wt was greater. However, contrary to the finding of Andy et al., age was not a viable predictor of BP in the study of Balogun et al. They attributed this inconsistency to age restriction (1-20 years and 8-20 years, resp.).

The reason why weight should preferentially predict systolic and why age preferentially predicts diastolic BP in children is open to speculation. However, it is known that $\mathrm{BP}$ rises with age but SBP increases more than DBP [14]. Also, increases in cardiac output increase the SBP, whereas increases in peripheral resistance increase DBP. Our finding suggests that increasing Wt may be associated with increase cardiac output while ageing may be associated more with increasing peripheral resistance thus explaining their respective correlations to each other.

Furthermore, age range of subjects seems an important factor in determining anthropometric marker for BP and hypertension. The age range of the current cohorts was 6-14 years, and the 95th centile BP was found to be $121 / 80 \mathrm{mmHg}$. By using this centile as the "cutoff" diagnostic criteria for hypertension $[15,16], 8 \%(N=81)$ prevalence of hypertension was found. In contrast Balogun et al. [4] found the 95th centile BP to be $133 / 92 \mathrm{mmHg}$ and a prevalence of $4 \%$. Therefore, the higher BP range may be attributed to the influence of the older (15-20 years) and most likely heavier subjects in their study.

Apart from Wt and age, AC (2.0\%), and BMI (1.6\%) were the other predictors of SBP, while AC (4.6\%) and age (0.7) were predictors of HR. The correlation between PI and some cardiovascular parameters was also significant. Our findings are consistent with reports from other populations $[9,11,17]$. Voors et al. [17] found PI to be one of the 
most important contributors to the associated variation in BP levels of American children. The important contributions of $\mathrm{AC}$ and BMI to the prediction of $\mathrm{BP}$ and $\mathrm{HR}$ are to be expected because of their known correlation to adiposity. Previous studies have shown that abdominal circumference was the most practical anthropometric measurement for assessing a patient's abdominal fat content and that AC correlates with the amount of fat in the abdomen $[7,9,12]$. Thus, it is an indicator of the severity of abdominal obesity. The present study found that AC correlated more $(r=0.48$, $P<.01)$ than BMI $(r=0.39, P<.01)$ with SBP in Nigerian children, a finding that agrees with the other reports $[7,9]$. These two studies reported that AC correlated more than BMI with cardiovascular risk factors and most strongly with insulin and SBP.

There was no significant difference in the cardiovascular parameters of male and female pupils. This finding agrees with the report of Balogun et al. [4] who reported no significant difference in resting BP of Nigerian boys and girls. This is in contrast with the report of Oviasu et al. [6] who observed significant difference in the BP of male and female children in their study of subjects with age range similar to the present cohort. These differences in observation may reflect ageing effect, ethnic, or regional variations in the relationship between anthropometric and cardiovascular indices of children $[6,9,14]$. This is more so because gender differences in growth pattern have long been known and ethnic and rural-urban differences in body somatotypes and sensory characteristics had been reported $[18,19]$. Further work will be needed to clarify this trend.

\section{Significance of the Study}

This study has revealed that Wt is a more viable predictor of SBP, while age predicts DBP better and AC predicts cardiovascular risk. Also, the prevalence of hypertension is increasing among Nigerian children. Based on these findings, it is recommended that body Wt norms be used in evaluating abnormal SBP while using age to evaluate abnormal DBP levels in Nigerian school-aged children. AC should be included as an anthropometric predictor of resting BP and $\mathrm{HR}$ in this population with a call for more action towards the prevention of childhood hypertension in Nigeria.

\section{Conclusion}

Significant correlations exist between age, Ht, Wt, BMI, AC, and BP with Wt being a more viable predictor of SBP and age a more viable predictor of DBP. Body weight norms should be used in evaluating abnormal SBP levels, while age should be used to evaluate abnormal DBP levels in Nigerian children.

\section{References}

[1] World Health Organization, "World Report," WHO, Geneva, Switzerland, 1998.

[2] L. Weinehall, B. Ohgren, M. Persson et al., "High remaining risk in poorly treated hypertention: 'the rule of halves' still exists," Journal of Hypertension, vol. 20, pp. 2081-2088, 2002.
[3] S. H. Zinner, L. F. Martin, F. Sacks, B. Rosner, and E. Kass, "A longitudinal study of blood pressure in children," American Journal of Cardiology, vol. 100, no. 6, pp. 437-442, 1975.

[4] J. A. Balogun, V. A. Obajuluwa, O. K. Abereoje et al., "Anthropometric determinants of resting blood pressure and heart rate of Nigerian school children," Annals of Tropical Paediatrics, vol. 10, no. 4, pp. 425-431, 1990.

[5] R. A. Adedoyin, C. E. Mbada, M. O. Balogun et al., "Prevalence and pattern of hypertension in a semiurban community in Nigeria," European Journal of Cardiovascular Prevention and Rehabilitation, vol. 15, no. 6, pp. 683-687, 2008.

[6] V. O. Oviasu, W. Alakija, and K. A. Oyarebu, "Differences in arterial pressure and body build in the first and second decades of life in urban and rural Nigerians," Tropical Cardiology, pp. 161-164, 1981.

[7] S. C. Savva, M. Tornaritis, M. E. Savva et al., "Waist circumference and waist-to-height ratio are better predictors of cardiovascular disease risk factors in children than body mass index," International Journal of Obesity, vol. 24, no. 11, pp. 1453-1458, 2000.

[8] M. Gus, S. C. Fuchs, and L. B. Moreira, "The association between different measurements of obesity and the incidence of hypertension," American Journal of Hypertension, vol. 17, no. 1, pp. 50-53, 2004.

[9] R. Y. Sung, C. C. Yu, K. C. Choi et al., "Waist circumference and body mass index in Chinese children: cut-off values for predicting cardiovascular risk factors," International Journal of Obesity, vol. 31, no. 3, pp. 550-558, 2007.

[10] M. F. Lean, T. S. Han, and C. E. Morrison, "Waist circumference as a measure for indicating need for weight management," British Medical Journal, vol. 311, no. 6998, pp. 158-161, 1995.

[11] B. D. Cox, M. J. Whichelow, and A. T. Prevost, "The development of cardiovascular disease in relation to anthropometric indices and hypertension in British adults," International Journal of Obesity, vol. 22, no. 10, pp. 966-973, 1998.

[12] M. F. Steele and J. B. Spurgeon, "Body size, body form, and nutritional intake of Black girls age 9 years living in rural and urban regions of eastern North Carolina," Growth, vol. 47, no. 2, pp. 207-216, 1983.

[13] J. J. Andy, G. O. A. Ladipo, S. P. Owolabi et al., "Blood pressure distribution of Nigerians in the first two decades of life," Annals of Tropical Paediatrics, vol. 5, no. 3, pp. 113-118, 1985.

[14] W. F. Ganong, Review of Medical Physiology, Lange Medical, Los Altos, Calif, USA, 15th edition, 2001.

[15] S. Londe, J. J. Bourgoignie, A. M. Robson, and D. Goldring, "Hypertension in apparently normal children," The Journal of Pediatrics, vol. 78, no. 4, pp. 569-573, 1971.

[16] C. W. Buck, "The persistence of elevated blood pressure first observed at age five," Journal of Chronic Diseases, vol. 26, no. 2, pp. 101-106, 1973.

[17] A. W. Voors, T. A. Forster, R. R. Frerichs, L. S. Webber, and G. S. Berenson, "Studies of blood pressure in children aged 5-14 years in a total biracial community: the Bogalusa heart study," Circulation, vol. 54, pp. 319-327, 1976.

[18] B. O. Onyejeme, E. C. Onyeneke, and G. E. Erigymremu, "The effect of social and cultural variables on the treatment of pain in Eastern part of Nigeria-epidemiological study," in Proceedings of the 10th World Congress on Pain, p. 79, Sandiego, Calif, USA, August 2002.

[19] M. O. Egwu and V. C. B. Nwuga, "Relationship between low back pain and life-stressing events among Nigerian and Caucasian patients," Physiotherapy, vol. 94, no. 2, pp. 133-140, 2008. 


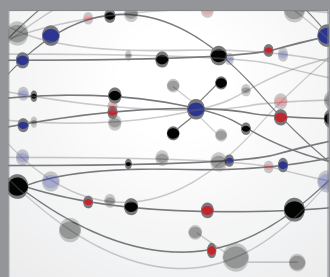

The Scientific World Journal
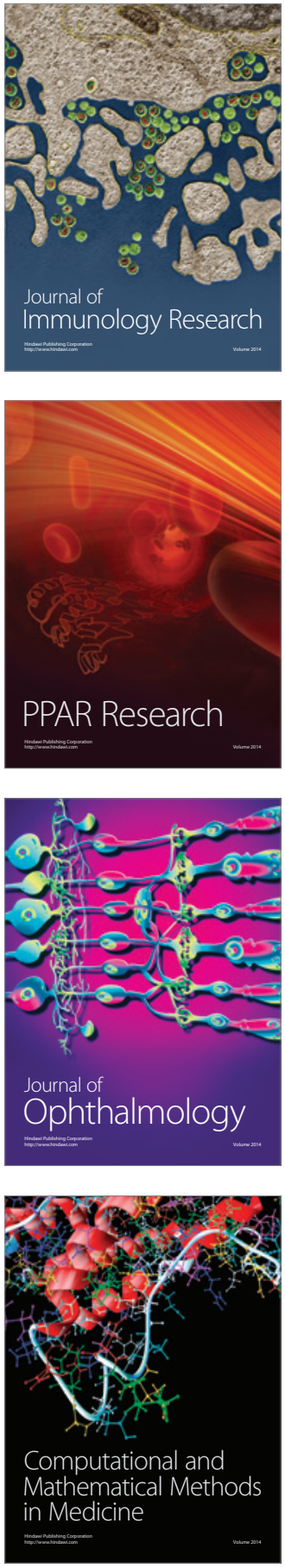

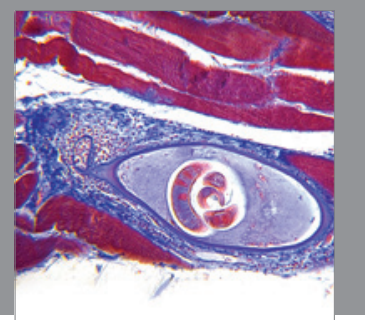

Gastroenterology

Research and Practice
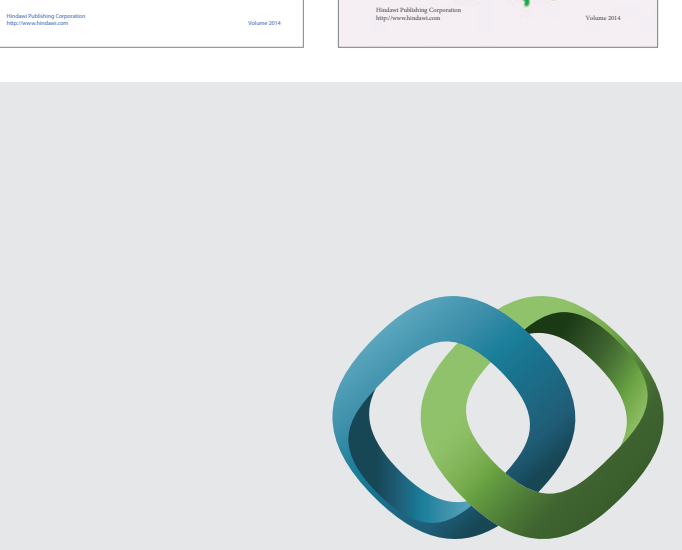

\section{Hindawi}

Submit your manuscripts at

http://www.hindawi.com
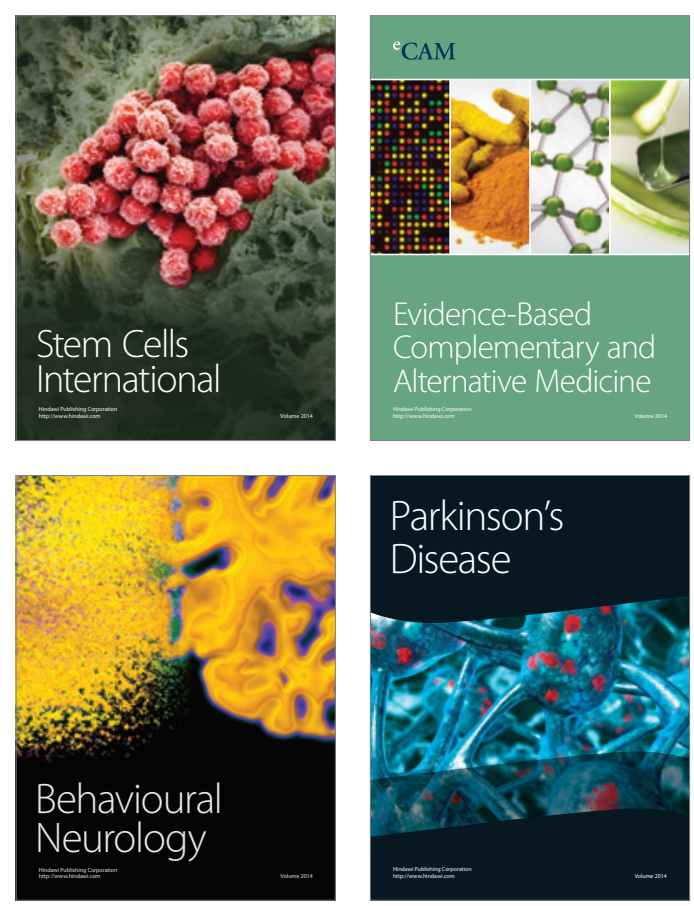

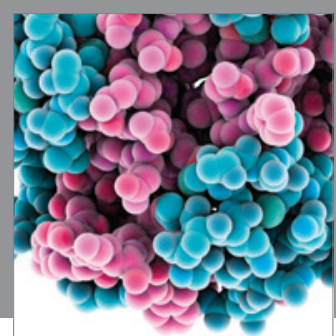

Journal of
Diabetes Research

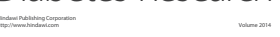

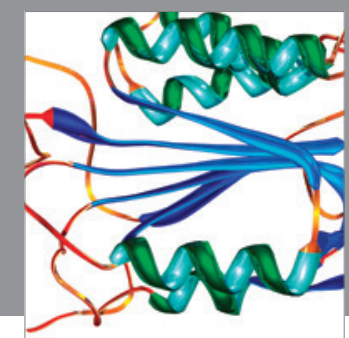

Disease Markers
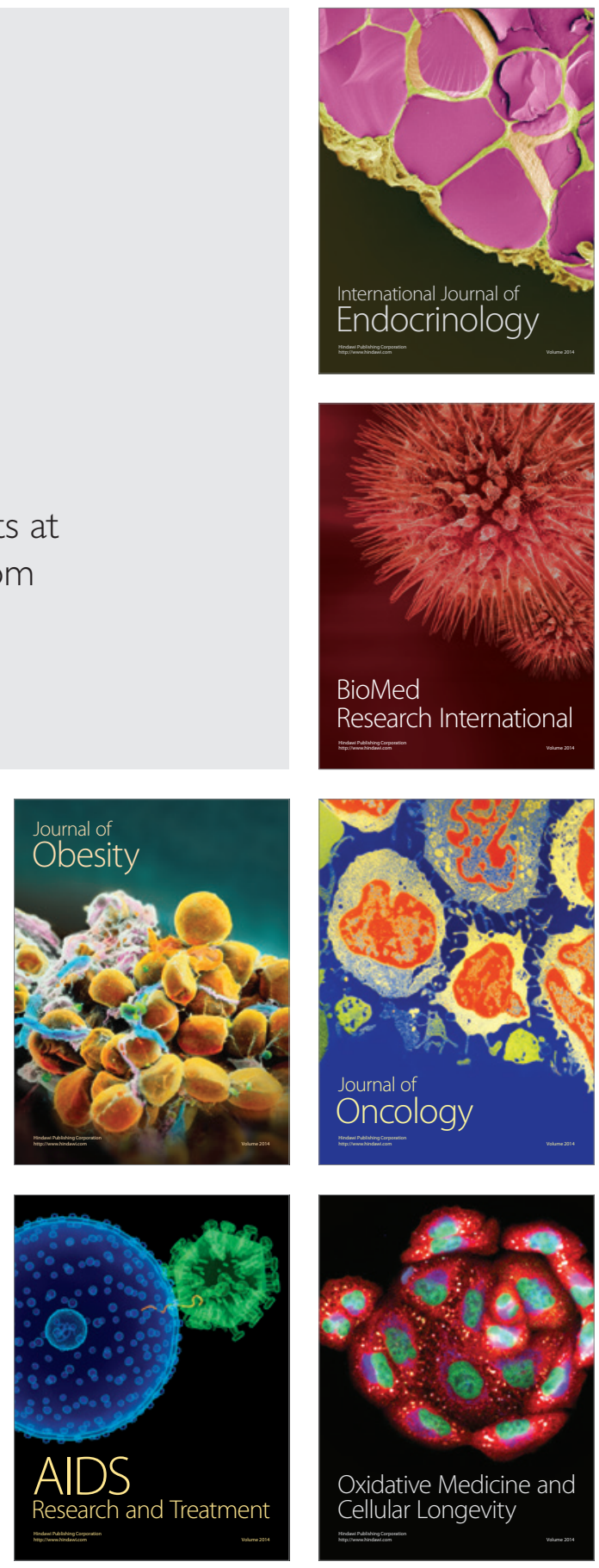